University of Denver

Digital Commons @ DU

Fuel Efficiency Automobile Test Publications Fuel Efficiency Automobile Test Data Repository

2008

A Decade of On-road Emissions Measurements

Gary A. Bishop

Donald H. Stedman

Follow this and additional works at: https://digitalcommons.du.edu/feat_publications

Part of the Environmental Chemistry Commons

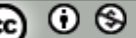

This work is licensed under a Creative Commons Attribution-NonCommercial 4.0 International License 


\title{
A Decade of On-road Emissions Measurements
}

\author{
Gary A. Bishop* and Donald H. Stedman \\ Department of Chemistry and Biochemistry \\ University of Denver, Denver, Colorado 80208
}

*To whom correspondence should be made; email: gbishop@du.edu

\begin{abstract}
A multi-year, on-road emission measurement program carried out in the cities of Chicago, IL, Denver, CO, Los Angeles, CA and Phoenix, AZ shows large, fuel specific tailpipe emissions reductions at all of the sites for carbon monoxide (CO), hydrocarbons (HC) and nitric oxide (NO). CO emissions decrease between 56\% (Denver) and 71\% (Chicago), HC emissions decrease between 27\% (Phoenix) and 63\% (Denver) and NO emissions have dropped between 48\% (West LA) and 68\% (Chicago). Three observed factors common to all of the sites are that the emission reductions are occurring in vehicles of all ages, that the influence of engine load on fuel specific emissions, especially for $\mathrm{CO}$ and $\mathrm{NO}$, is reduced and that fleet averaged emission deterioration is near zero for model years newer than 2001 and older than 1990. These nationwide data sets imply that the majority of these on-road emissions reductions are the result of continued improvements in function and durability of vehicle emission control systems and that inspection and maintenance and fuel reformulation programs have only played a minor role.
\end{abstract}




\section{Introduction}

Since the early fifties when A. J. Haagen-Smit first linked automobile exhaust with the formation of urban ozone, the study of vehicle exhaust emissions has provided an important foundation for developing public health policy in the United States $(1,2)$. Those policies have resulted in ever-shrinking national tailpipe and evaporative new vehicle emissions standards. Fuel reformulation mandates, state controlled vehicle inspection and maintenance (I/M) programs and other transportation control measures such as high occupancy vehicle lanes have also been implemented. These efforts have been primarily directed at reducing levels of CO and ground-level ozone, a major component of urban smog that is produced by the photochemical reaction of nitrogen oxides $\left(\mathrm{NO}_{\mathrm{x}}\right)$ and volatile organic hydrocarbons (VOCs). As of 2002, onroad vehicles were estimated to be the single largest source for these major atmospheric pollutants, contributing $82 \%$ of the $\mathrm{CO}, 45 \%$ of the VOCs, and $56 \%$ of the $\mathrm{NO}_{\mathrm{x}}$ to the national emission inventory (3).

In the mid-nineties the Coordinating Research Council proposed the collection of on-road tailpipe emissions data from various groups with the purpose of monitoring the long-term onroad emission trends of the US vehicle fleet (4). The idea was to establish comparable sites around the country where approximately 20,000 tailpipe measurements of CO, HC, NO, vehicle information, speed and acceleration could be collected at the same location over regular intervals on fully warmed up vehicles using on-road vehicle remote sensing systems (5). The University of Denver began collecting measurements at a site in the Northwest suburbs of Chicago, IL in 1997 and in 1998 at sites in Denver, CO; Los Angeles, CA and Phoenix, AZ (6). 


\section{Experimental}

Criteria for site selection in all of the cities required a single lane roadway, preferably with a positive grade; sufficient traffic volume to allow the collection of $20,000+$ vehicle records in a week with no prospects for site reconstruction in the foreseeable future. All of the sites listed in Table 1 are curved interchange or on-ramps adjacent to major freeways. It should be noted that both Los Angeles and Phoenix required changes in the initial sampling locations. In Los Angeles, construction projects surrounding our Riverside measurement site made data collection after 2001 unfeasible, and the site in Phoenix was moved between the 1998 and 1999 measurements to a site with more positive acceleration patterns. Sampling was originally slated to be yearly but, beginning in 2001, it was decided that biannual measurements were sufficient. In addition to the four major cities, we have also explored additional cities to add to the list and collected measurements in Omaha, NE and Tulsa, OK. These two cities differ from the other sites in that their vehicle fleets have never been subject to any type of local I/M or fuel reformulation program. All of the twenty nine data sets including more than three quarters of a million measurements and summary reports are available for download from our website at www.feat.biochem.du.edu.

The same University of Denver remote vehicle exhaust sensor (\#3002) was used to collect all of the data sets listed in Table 1. The instrument consists of a source and detector unit consisting of a non-dispersive infrared (IR) component for detecting $\mathrm{CO}$, carbon dioxide $\left(\mathrm{CO}_{2}\right)$, and $\mathrm{HC}$, and a dispersive ultraviolet (UV) spectrometer for measuring NO arranged bi-statically across the roadway and has been fully described in the literature $(5,7)$. As a vehicle passes between the source and detector, its exhaust plume hopefully intersects with the collinear IR and UV beams allowing absorption measurements of all the species. Since the path length of the plume is 
Table 1. Summary of Measurement Locations, Collection Month and Years.

\begin{tabular}{|c|c|c|c|}
\hline City & Location / Roadway Grade (deg) & Month & Years Data Collected \\
\hline Chicago, IL & $\begin{array}{l}\text { Algonquin Rd. } \\
\text { to EB I-290 (SH 53) / 1.0 }\end{array}$ & September & $\begin{array}{l}1997 \text { - 2000, } \\
\text { 2002, 2004, } 2006\end{array}$ \\
\hline Denver, CO & NB I-25 to WB $6^{\text {th }}$ Ave $/ 4.6^{\circ}$ & January & $\begin{array}{l}1999-2001, \\
2003,2005,2007^{\text {a }}\end{array}$ \\
\hline LA / Riverside, CA & NB 91 to WB $60 / 4.4^{\circ}$ & June/July & $1999-2001$ \\
\hline West LA, CA & SB La Brea Ave to EB I-10 / 2.0 & October & $\begin{array}{l}1999^{b}, 2001,2003, \\
2005\end{array}$ \\
\hline Phoenix, AZ ${ }^{\mathrm{C}}$ & $\begin{array}{l}\text { WB Sky Harbor Blvd. } \\
\text { to SB } 143 / 1.3^{\circ}\end{array}$ & November & $\begin{array}{l}\text { 1999, 2000, 2002, } \\
\text { 2004, } 2006\end{array}$ \\
\hline Omaha, NE & $\begin{array}{l}\text { SB I-680 to EB Dodge Rd / } 2.7^{\circ} \\
\text { NB } 84^{\text {th }} \text { St. to EB I-80 / } 2.2^{\circ} \\
\text { NB }-680 \text { to WB Dodge Rd } / 3.1^{\circ}\end{array}$ & September & $\begin{array}{l}2002 \\
2002 \\
2004\end{array}$ \\
\hline Tulsa, OK & WB US 64 to SB US $169 / 2.6^{\circ}$ & September & 2003 \\
\hline
\end{tabular}

${ }^{\mathrm{a}}$ Measurements funded by the University of Denver.

${ }^{\mathrm{b}}$ Measurements funded by the Steven and Michelle Kirsh Foundation.

${ }^{\mathrm{c}}$ Measurements were collected in 1998 at WB I-10 to NB US 143 that are not listed here.

unknown and is highly variable from vehicle to vehicle, the remote sensor can only directly measure the ratios of $\mathrm{CO}, \mathrm{HC}$ and $\mathrm{NO}$ to exhaust $\mathrm{CO}_{2}$. These ratios are constant for a given exhaust plume. With a small correction for the fact that an NDIR HC reading is about half a total carbon FID reading by doubling the $\mathrm{HC} / \mathrm{CO}_{2}$ ratio one can convert the measured ratios into fuel specific emissions of grams of pollutant per $\mathrm{kg}$ of fuel $(5,8)$. 
Quality assurance calibrations are performed as dictated in the field by the atmospheric conditions and traffic volumes. A puff of gas containing certified amounts of $\mathrm{CO}, \mathrm{CO}_{2}$, propane and NO (Praxair) is released into the instrument's path, and the ratios measured. The observed ratios are then used in the remote sensor's software to scale the measured emission ratios obtained from the passing vehicles. These calibrations account for day-to-day variations in instrument sensitivity and variations in ambient $\mathrm{CO}_{2}$ levels caused by atmospheric pressure and instrument path length. Since propane is used to calibrate the instrument, all HC measurements reported by the remote sensor are as propane equivalents.

A freeze-frame video image of the license plate of each vehicle is recorded along with the emission measurements. The license plate information is used to obtain non-personal vehicle information from the local registration records. In addition to emission measurements, a pair of parallel infrared beams (Banner Industries) 6 feet apart and approximately 2 feet above the roadway is used to measure the speed and acceleration of the vehicles. Previous studies have shown that the remote sensor is capable of CO measurements that are correct to within $\pm 5 \%$ of the values reported by an on-board gas analyzer, and within $\pm 15 \%$ for $\mathrm{HC}(9,10)$. The NO channel has been estimated to have a detection limit $( \pm 3 \&)$ of $25 \mathrm{ppm}$ for NO, with an uncertainty of $\pm 5 \%$ of the reading at higher concentrations (7).

Measurements at each site are generally collected during daylight hours (Phoenix is an exception where some measurements are collected before sunrise during the morning commute) and only during dry roadway conditions. An excess of data is collected at each site so that after the data reduction process which eliminates invalid gas measurements, unreadable and out of state plates (this typically eliminates 20 to $30 \%$ of the attempted measurements), a database results with approximately 20,000 records that contain at least valid emission measurements for 
$\mathrm{CO}$ and matching vehicle registration data. There is no statistically significant difference between the mean emissions of all valid measurements and of the plate-matched fleet.

\section{Results and Discussion}

The fuel specific mean emissions for CO, HC and NO are plotted in Figure 1 for Chicago, Denver, Los Angeles (2 sites) and Phoenix for each of the measurement years listed in Table 1. These means have been calculated using all of the valid emissions data (unless noted, the data were not required to include a valid speed and acceleration measurement) in each database and have not been filtered in regards to fuel type (gasoline or diesel), driving mode, vehicle type or model year. The uncertainty bars plotted for West LA and Chicago are standard errors of the means calculated from each daily measurement mean and are representative of the magnitude of uncertainty for all of the sites. The mean HC values have been adjusted to compensate for a variable systematic offset in the measurements (11). The source of this offset, restricted to the HC channel, is thought to be a product of the optical alignment of the HC and reference IR channels combined with the very low HC signals from the lowest emitting HC vehicles today. This setup specific offset results in the entire HC distributions zero point being artificially increased or decreased. Site by site calculation of the offset is accomplished by computing the mode and means of the newest model year vehicles and assuming these vehicles emit negligible levels of HC, using the lowest of either of these values to adjust the offset. Since we assume these vehicles emit only small amounts of HC, such an adjustment will only err slightly towards clean because the true offset will be a value somewhat less than the average of the cleanest model year and make. The offset is only used for comparing sites and is not included in any of the archived databases. 

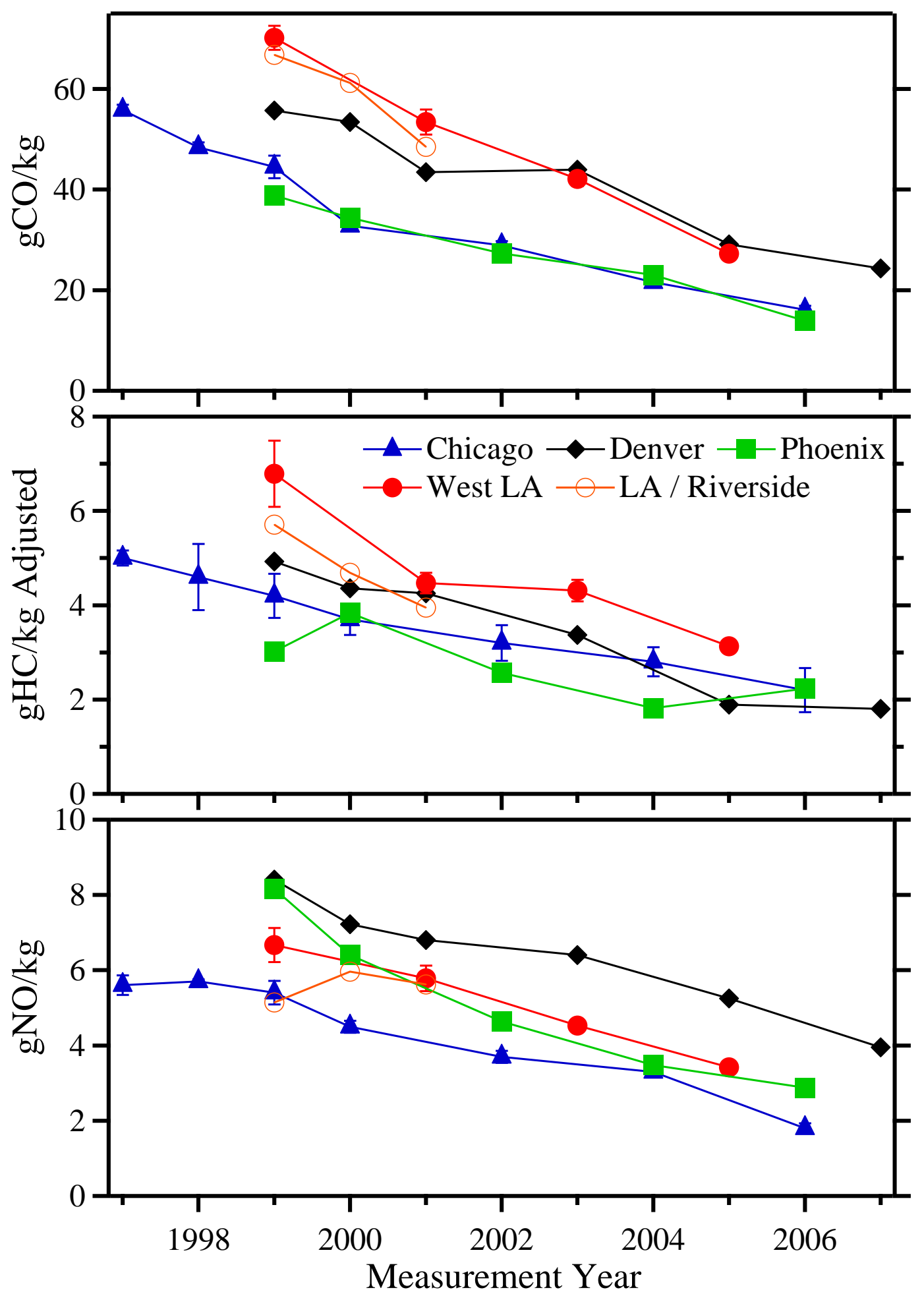

Figure 1. Mean, fuel specific emissions plotted by measurement year. Standard errors of the mean calculated from each site's daily measurement means are plotted for the Chicago and West LA sites and are representative of the uncertainties for all sites. 
The standardization of measurement sites and sampling times was an attempt to lower year to year variability in the measurements by minimizing changes in fleet characteristics. But since the data in Figure 1 are not age normalized, year to year changes in the level of new car purchases changes the age of the vehicle fleets measured and their mean emission levels vary with these changes despite controlling for location and sampling time. In addition, the weather is another variable that cannot be controlled from year to year and will slightly affect emissions for example by changing the amount of vehicle air conditioning that is being used.

Some of the differences in emissions shown in Figure 1 between the four sites can be accounted for by differences in fleet age and driving mode. Chicago and Phoenix have the newest fleets with average fleet ages of around 5 years while Denver and West LA (despite the large geographical difference within the LA basin between the West LA and Riverside sites the fleet ages and emissions are comparable) have older fleets of 7 and 6 years old, respectively. These age differences are reflected the strongest in the differences in CO emissions. The Denver site has the steepest grade $\left(4.6^{\circ}\right)$ and therefore highest driving loads, which is one factor that contributes to the larger observed NO emissions. Other fleet differences that do not markedly impact the emissions picture are that the Chicago fleet has the lowest percentage of light trucks and diesel vehicles. All of the western sites have a much higher percentage of light trucks and Phoenix (5.4\% diesels) and Denver (3.3\% diesels) have the largest percentages of diesel vehicles.

Each site plotted in Figure 1 has experienced large, fuel specific, fleet averaged emission reductions for $\mathrm{CO}, \mathrm{HC}$ and $\mathrm{NO}$ emissions. Using the beginning and ending year means, $\mathrm{CO}$ emission decreases range between 56\% (Denver) and 71\% (Chicago), HC emission reductions range between 27\% (Phoenix) and 63\% (Denver) and NO emissions have dropped between 48\% 
(West LA) and 68\% (Chicago). During the decade measurement span, the fleet in Chicago has become newer by 0.7 years and the fleets in Denver, West LA and Phoenix have become older by approximately 0.4 years. Reductions of similar magnitudes have been noted by other authors with other data sets and for other species reflecting what we believe to be a nationwide trend (3, 12-14).

There are at least three common factors that can be supported with data from any of the four sites contributing to the large measured reductions in fuel specific emissions. The first is that the reductions are observed across all vehicle age groups. Figure 2 uses data from Phoenix and plots emissions by vehicle age for the five data sets collected in Phoenix. The ten to twelve year old vehicles are averaged together to have a sufficient number of vehicles. The lines are least square fits to the ten to twelve year old vehicles and the one to five year old fleets. By keeping vehicle age constant, the vehicle model years are incrementally increasing during the seven year time span. For example the five year old vehicles (1994 models) measured in 1999 are part of the ten to twelve year old average in 2006.

In absolute terms, the ten to twelve year old vehicles show the largest improvements, but the one to five year old vehicles show a similar reduction on a percentage basis. One way to observe this is to notice the spread between one year old vehicles in 1999 (1998 models) and five year old vehicles (1994 models), and then compare that spread with one year old vehicles measured in 2006 (2005 models) and five year old vehicles (2001 models). This spread has contracted significantly for all three pollutants during the seven years (15). It is important to point out that only by this process of annual or biennial sampling can the difference between different model year fleets and the effect of age on a given model year be separated. 

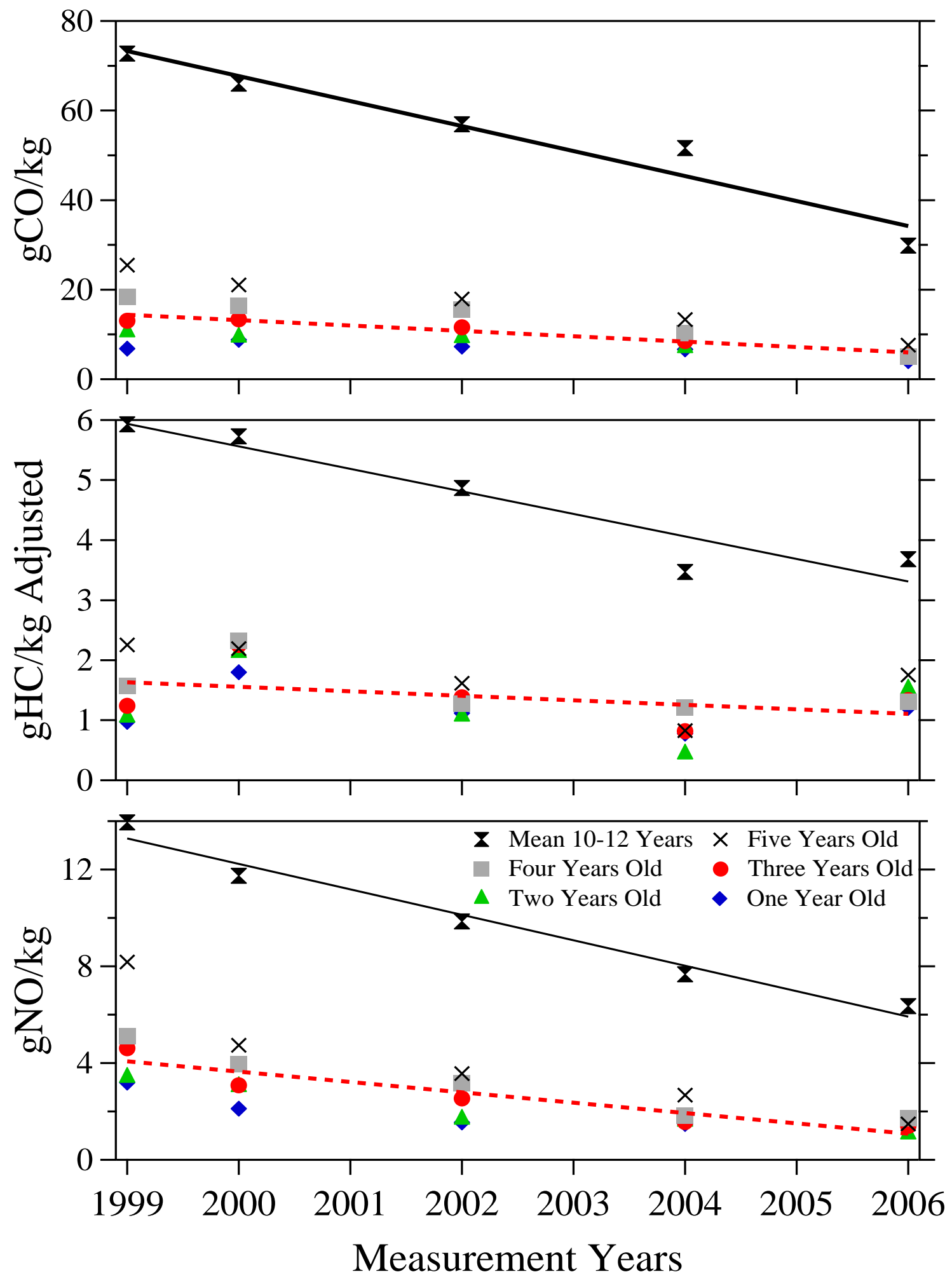

Figure 2. Mean, fuel specific emissions for selected vehicle age groups from the Phoenix measurement site plotted by measurement year. The lines are least squares fit to all of the data that makes up the subsets. 
The second common factor is the gradual reduction of the influence of engine load on fuel specific emissions. Using the road grade and speed and acceleration measurements that we collect and an equation proposed by Jimenez, we can calculate the instantaneous vehicle specific power (VSP) of an on-road vehicle in kilowatts per metric tonne (16). The West LA site is a traffic light controlled on-ramp and Figure 3 plots emissions data that has valid speed and acceleration measurements against VSP for the four data sets collected. In 1999, the CO emissions versus VSP pattern was nearly bowl shaped with emissions roughly tripling between its minimum VSP at 15 (approximately $18 \mathrm{mph}$ and a $1.7 \mathrm{mph} / \mathrm{s}$ acceleration rate) and 30 KW/tonne (approximately $22 \mathrm{mph}$ and a $4.4 \mathrm{mph} / \mathrm{s}$ acceleration rate). The emission difference between these two load points in 2005 is statistically indistinguishable meaning that far fewer vehicles are being forced into power enrichment during accelerations onto freeways. With lower $\mathrm{CO}$ emissions it would be reasonable to expect increases over time in NO emissions between these same load points. What we find is just the opposite with NO emissions also declining and the emissions versus load curve flattening as with CO despite more vehicles operating near stoichiometric conditions.

Finally, the third factor observed is that on-road fleet averaged emission deterioration is near zero for model years newer than 2001 and older than 1990. We have combined the emissions data from all four cities (to increase the representation of older model year vehicles) into a plot of fuel specific emissions versus age that can be used to quantify the observed on-road emission deterioration rates. Vehicle age has been defined as the difference between the year of measurement and the vehicle model year. Assuming that vehicle emissions deterioration is a linear process we can fit a straight line to each model year grouping where the slope of that line is the grams of emissions $/ \mathrm{kg}$ of fuel/year deterioration rate. Figure 4 is a plot of the linear 

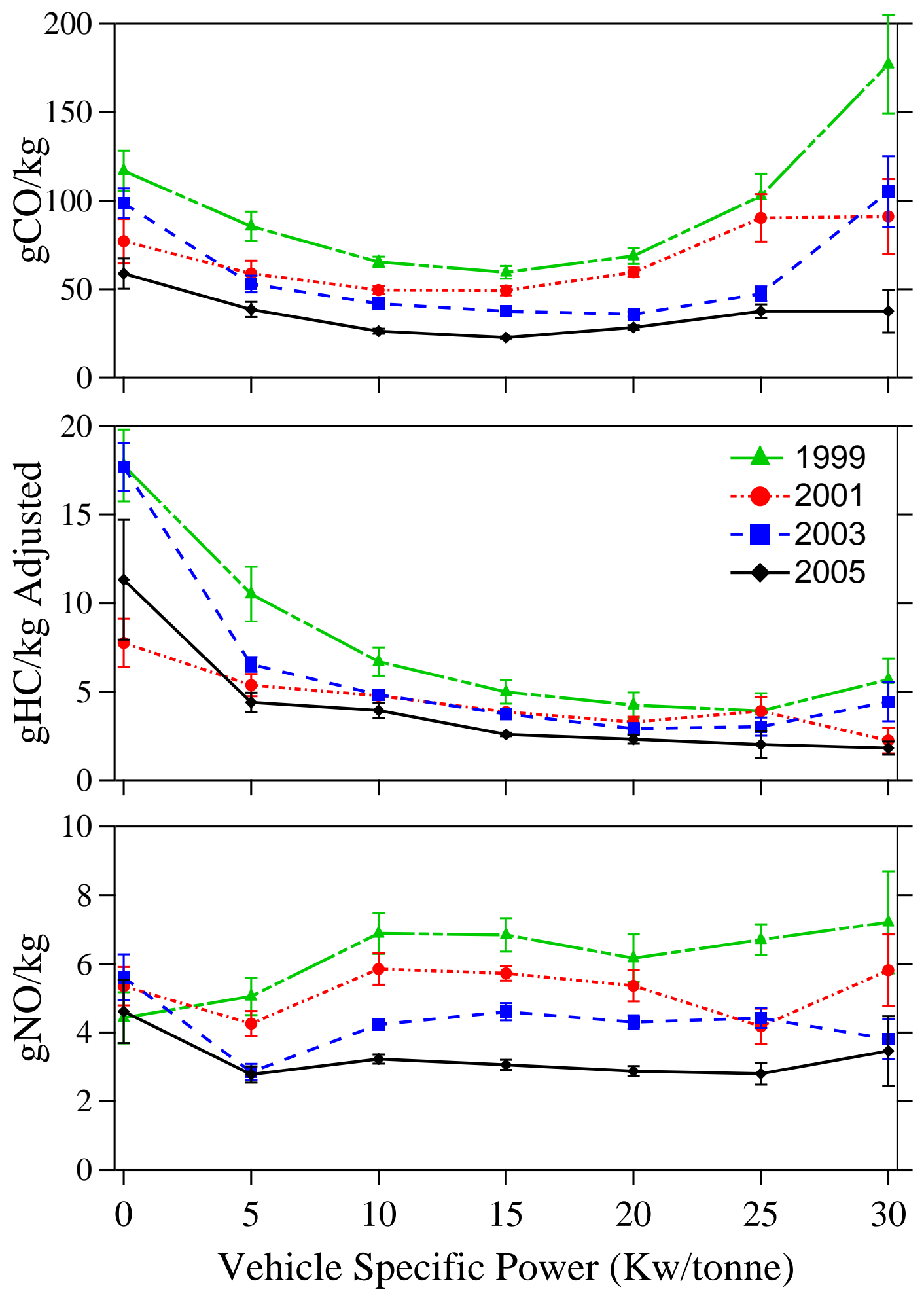

Figure 3. Mean, fuel specific emissions for the four years of data collected at the West LA site plotted as a function of Vehicle Specific Power. Only emissions data with valid speed and acceleration measurements are plotted and the uncertainties displayed are standard errors of the means calculated using the daily means. 


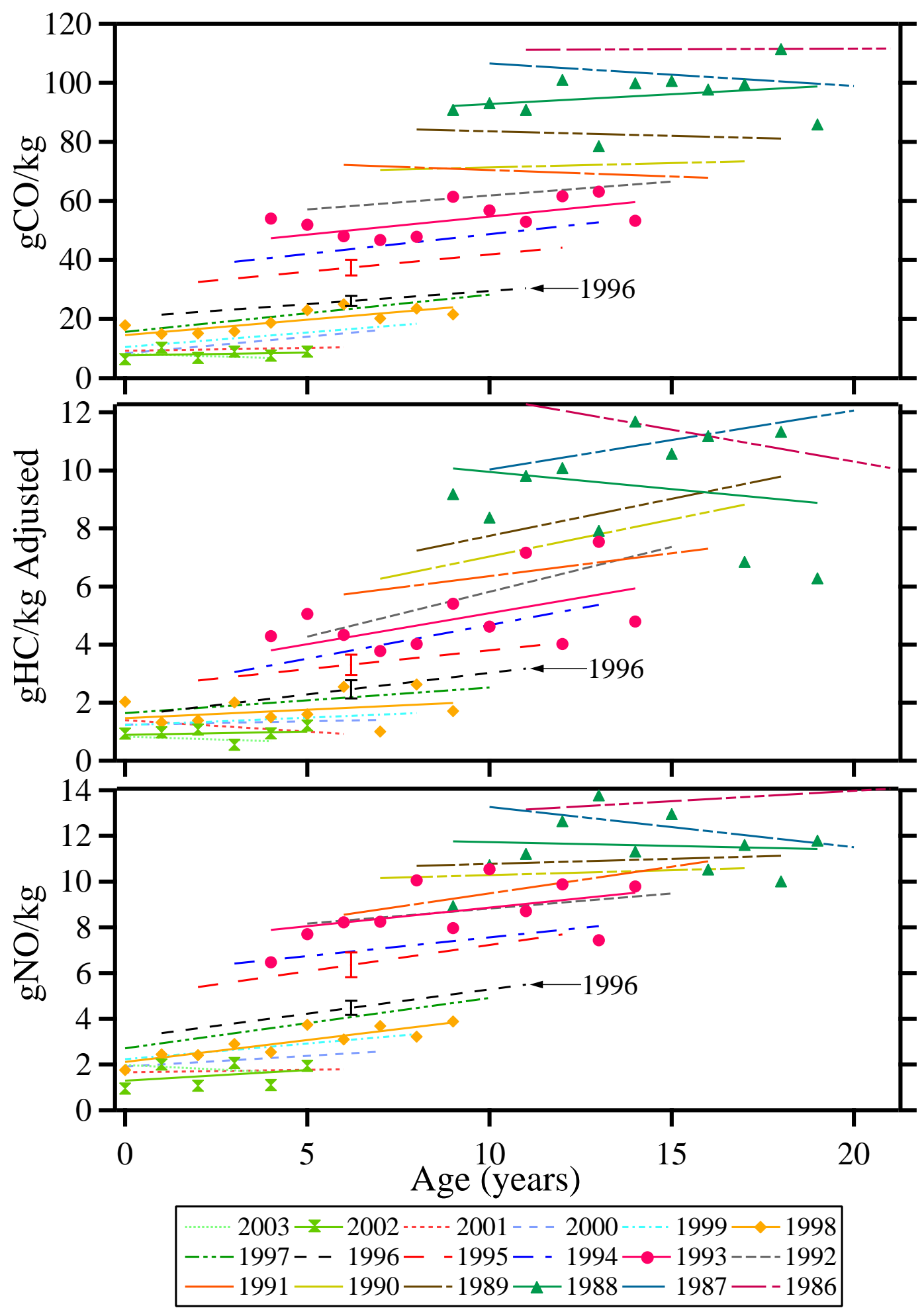

Figure 4. Linear least square fits to mean, fuel specific vehicle emissions as a function of age from the combined data of Chicago, Denver, West LA and Phoenix. The data are grouped by model year beginning with 2003, which is the first model with at least three measurements, and go back to the 1986 model year. The data used to construct the linear fits are displayed for model years 2002, 1998, 1993 and 1988. The error bars plotted for model years 1995 and 1996 are $95 \%$ confidence limits for the midpoints. 
emission trends for model years 2003 (the first year with at least three measurements) to 1986. The actual data points used to construct the linear fits are plotted for model years 2002, 1998, 1993 and 1988 to illustrate the noise in the data.

Two sources of noise important to mention are the sample size used to calculate the means and instrument noise. Vehicle emissions are gamma distributed and means sampled from a gamma distribution are highly sensitive to the number of samples (17). In Figure 4 mean samples per measurement year are 2000 samples for model year 2002, 1800 for 1998, 950 for 1993 and 450 for 1988 and the plotted data points show how the noise increases proportionately. The HC channel has the poorest signal to noise ratio of all the species measured due to a combination of the low levels emitted by the vehicles and a smaller absorbance cross section. This contributes to about a threefold increase in the relative noise levels in the HC data for similar sample sizes when compared to the CO or NO channels $(7,10)$. We have also introduced some additional data variability to the NO data sets by combining data collected during alternating years from sites with differing vehicle load profiles.

Three notables in Figure 4 are the generally stair step nature of emission differences between model years and an emissions gap between 1996 and 1995 models (significant at the 95\% confidence level) that also serves as a demarcation point where the stair steps change step sizes (smaller before 1996 and larger after). Any possible explanation for the emissions gap has to account for the fact that its presence is universal and we have shown upon analysis can be seen in all makes, models and types of vehicles. Three of the more obvious possibilities are extended emission component warranties, the introduction of the second generation of on-board diagnostic systems (OBDII) and a reduction in new vehicle emission standards. The extended warranties began with 1995 models and while OBDII was introduced with the 1996 models it was not 
accompanied by any new legislated reductions in per-mile emissions and was generally viewed as being aimed at reducing long-term vehicle emissions deterioration not reducing their initial emissions. However, as part of the changes that accompanied OBDII systems one of the more notable was the requirement to monitor catalyst efficiency that dictated the addition of two additional oxygen sensors, one before and after the catalyst. These sensors have allowed manufacturers to correct for any long-term drift that might occur with the manifold oxygen sensor and most importantly control the fuel trim on a cylinder by cylinder basis and produce lower emission levels of the size we have observed. $(18,19)$.

Figure 5 compares model year emission deterioration rates (the slopes of the lines plotted in Figure 4) with deterioration rates predicted by the U.S. Environmental Protection Agencies vehicle emissions model MOBILE6.2 (20). The uncertainty bars plotted with the on-road data are the standard error of the slope of the least square fit. The model output has been created using an input file (see supporting information) that models a winter and summer on-road scenario with no refueling emissions where the vehicles are subject to the Denver, CO I/M program. The deterioration rates plotted are for a vehicle fleet composed of 50\% light-duty gasoline vehicles and $25 \%$ each of light-duty gasoline trucks type 1 and 2 . The modeled data have been converted to gram/kg data assuming a fuel density of 726 grams/liter and the modeled $\mathrm{NO}_{2}$ data have been converted to NO for direct comparison with the on-road measurements.

Vehicles newer than model year 2001 and older than model year 1990 show little or no emissions deterioration and only for the HC data are the magnitudes of these rates similar between the measurements and the model. The model predictions are much too high for 1996 and newer model year $\mathrm{CO}$ and $\mathrm{NO}$ emissions. The modeled $\mathrm{CO}$ emissions deterioration rates begin their large decrease with model year 1998 due to the removal of sulfur from gasoline that 

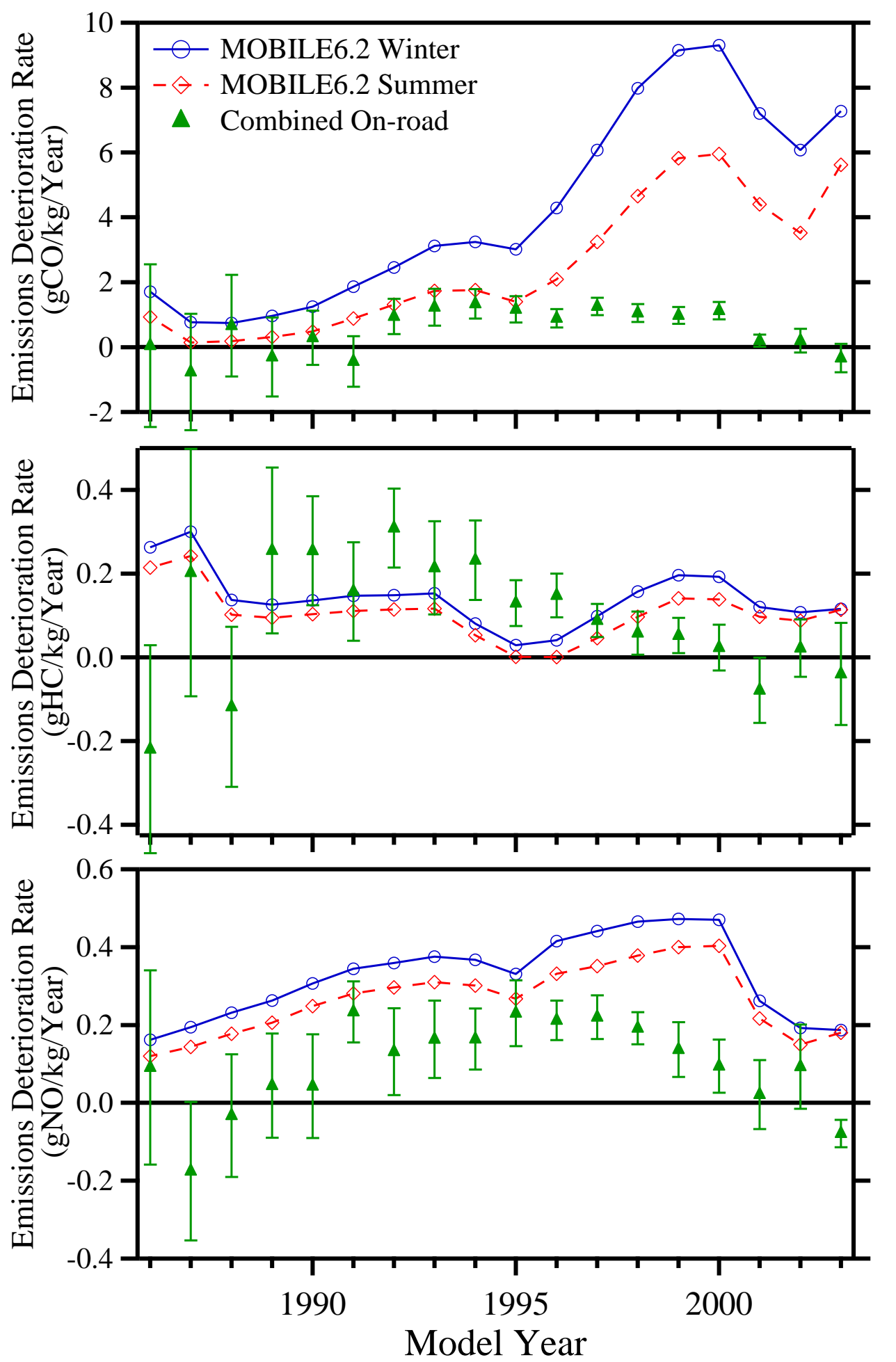

Figure 5. On-road emissions deterioration rates (see Figure 4) versus model year compared with emissions deterioration rates determined from the U.S. EPA's MOBILE6.2 vehicle emissions computer model. The uncertainty bars plotted with the on-road data are the standard error of the slope for the least squares fit. The MOBILE6.2 grams/gallon data have been converted to $\mathrm{g} / \mathrm{kg}$ assuming a fuel density of 726 grams/liter and the MOBILE6.2 $\mathrm{NO}_{2}$ emissions have been converted to NO equivalents for comparison with the on-road data. 
began in 2000 (21). While there is a noticeable on-road emissions break between model years 1995 and 1996 there is not a significant difference between the measured on-road emissions deterioration rates accompanying OBDII systems. These systems were designed to reduce emission deterioration rates by finding emission system failures sooner and alerting the driver to the need for repair. The similar deterioration rates suggest that emission system failure and repair is not the dominant factor (vehicle retirement rates and initial fleet emissions are others) determining on-road deterioration rates.

We have argued in the past that the majority of the on-road emissions reductions that have been observed are likely the result of continued improvements in function (i.e. three oxygen sensors) and durability of vehicle emission control systems and not state $\mathrm{I} / \mathrm{M}$ programs or fuel reformulations (15). To attempt and differentiate between emissions reductions from vehicle technology and state I/M programs and fuel mandates, we collected data in Omaha, NE and Tulsa, OK. Neither of these cities has ever been involved in any type of state I/M program nor have they required additional fuel reformulation. The uphill interchange ramp in Tulsa is the most comparable location to the other sites with a similar layout and driving mode.

We have shown previously that I/M programs export failing vehicles to outlying areas, thus producing artificial emission increases when those areas are compared to a neighboring I/M fleet $(22,23)$. Tulsa is geographically isolated in that it is buffered along all of the major commuting routes with at least one major metropolitan area without I/M between it and a city with an I/M program. For example, Oklahoma City is between Tulsa and Dallas to its south. These buffer cities, along with the increased distances from major I/M cities, should work to limit the number of emission failing vehicles being imported to the Tulsa area allowing the collection of emission data from a true non-I/M control fleet. 
Figure 6 is a series of comparison plots between data collected in Tulsa, OK in September 2003 and in West LA in October 2003 for the three measured pollutants. Since there is only a month between the two collection periods, changes in fleet age are minimized. Plotted are the mean emissions for vehicle model years 2003 to 1986 and the uncertainty bars are standard errors of the mean calculated using each sites daily means. The line is a 1:1 line drawn for a visual reference. The agreement between the two data sets is apparent not withstanding the increased noise in the older model years due to the shrinking sample size. This agreement suggests that the large emission reductions that we have observed at the West LA site have also occurred in Tulsa. It also suggests that any site specific fuel effect on these three emission species, are minor at best, although fuel reformulations have been clearly shown to reduce other species such as benzene that are not measured in this study (14).

However, we do not wish to overemphasize the absolute agreement since socioeconomics plays a role in absolute vehicle emission levels even when age is controlled for as in this case (24). It is more important to compare the two sites emission versus age distribution and take advantage of the fact that the first four model years (the first four model years are not required to be inspected in CA) at each site have not been subject to an I/M inspection. Conventional wisdom and the MOBILE computer model predicts that an I/M program will change the shape of this distribution (i.e. Figure 6 should not be a straight line) after the first four model years to the extent that the program works to retard the normal emissions deterioration and that these benefits should accumulate over time $(25,26)$. The fact that vehicle emissions versus age in Tulsa, OK have a similar distribution (the linear relationship continues after the first four model years) when compared to vehicles in Los Angeles suggests that vehicle emission inspections in 


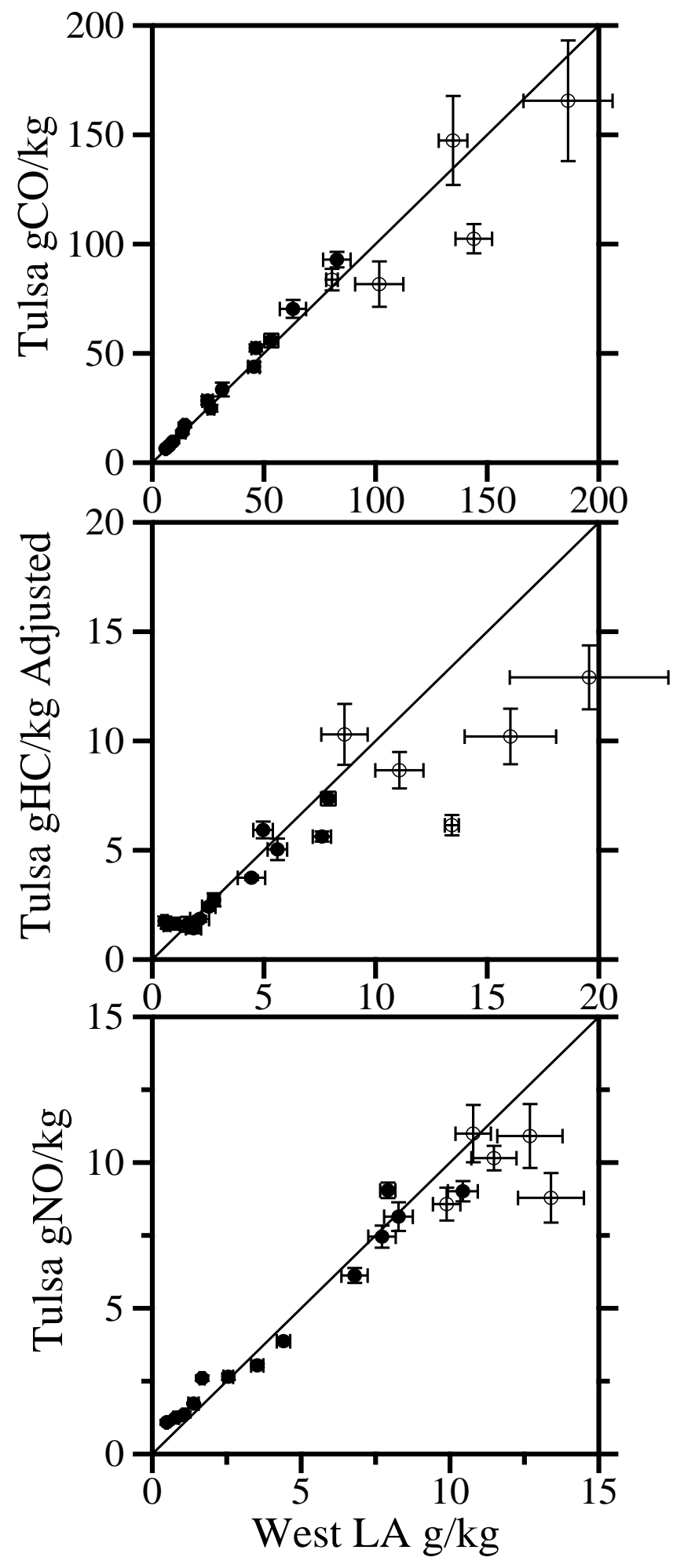

Figure 6. Fuel specific emissions comparison between the 2003 data sets collected in Tulsa, OK and West Los Angeles, CA for model years 2003 to 1986. The uncertainty bars plotted are standard errors of the mean calculated from the daily means at each site. The 1:1 line is plotted as a reference. 1990 to 1986 model years (open circles) with the most noticeable uncertainty bars constitute less than $12 \%$ of the West LA fleet and less than $6 \%$ of the Tulsa fleet. 
California should not be considered a major factor in the large on-road emission reductions observed at the West LA site (27).

Acknowledgements

The authors gratefully acknowledge the funding and support of the Coordinating Research Council under Contract E-23. We would also like to thank Dr. Steven Cadle for his help with the manuscript and Dr. Daniel Burgard, Dr. Peter Popp, Dr. Sajal Pokharel, Ryan Stadtmuller and Mitch Williams who helped to collect these data sets and the Colorado Department of Health and Environment for providing the MOBILE 6.2 input file. The authors would like to especially thank Annette Bishop who has helped bring meaning to all of these measurements by reading the more than three quarters of a million license plates.

Supporting Information Available

Listing of the MOBILE6.2 input file used to create the data used in generating Figure 5. This material is available free of charge via the Internet at http://pubs.acs.org.

Literature Cited

1. Haagen-Smit A. J.; Bradley, C. E.; Fox, M. M. Ozone formation in photochemical oxidation of organic substances. Indust. Eng. Chem. 1953, 45, 2086.

2. Haagen-Smit, A. J.; Fox, M. M. Photochemical ozone formation with hydrocarbons and automobile exhaust. J. Air Pollut. Control Assoc. 1954, 4, 105-109.

3. U. S. Environmental Protection Agency. National Air Quality and Emissions Trends Report, 2003 Special Studies Edition; EPA Publication 454-R-03-005; 2003. 
4. Coordinating Research Council. CRC Annual Report 1997, Alpharetta GA, 1997, 16.

5. Burgard, D. A.; Bishop, G. A.; Stadtmuller, R. S.; Dalton, T. R; Stedman, D. H. Spectroscopy applied to on-road mobile source emissions. Appl. Spect. 2006, 60, 135A-148A.

6. Popp, P.J.; Bishop, G.A.; Stedman, D.H. On-road remote sensing of automobile emissions in the Chicago area: year 1; Tech Report Coordinating Research Council E-23-4; University of Denver: Denver CO, 1998; Available at http://www.feat.biochem.du.edu.

7. Popp, P. J.; Bishop, G. A.; Stedman, D. H. Development of a high-speed ultraviolet spectrometer for remote sensing of mobile source nitric oxide emissions. J. Air \& Waste Manage. Assoc. 1999, 49, 1463-1468.

8. Singer, B. C.; Harley, R. A.; Littlejohn, D.; Ho, J.; Vo, T. Scaling of infrared remote sensor hydrocarbon measurements for motor vehicle emission inventory calculations. Environ. Sci. Technol. 1998, 32, 3241-3248.

9. Lawson, D. R.; Groblicki, P. J.; Stedman, D. H.; Bishop, G. A.; Guenther, P. L. Emissions from in-use motor vehicles in Los Angeles: A pilot study of remote sensing and the inspection and maintenance program. J. Air \& Waste Manage. Assoc. 1990, 40, 1096-1105.

10. Ashbaugh, L. L.; Lawson, D. R.; Bishop, G. A.; Guenther, P. L.; Stedman, D. H.; Stephens, R. D.; Groblicki, P. J.; Parikh, J. S.; Johnson, B. J.; Haung, S. C. On-road remote sensing of carbon monoxide and hydrocarbon emissions during several vehicle operating conditions; In PM10 Standards and Nontraditional Particulate Source Controls; Chow, J.C., Ono, D.M., Eds.; AWMA: Pittsburgh, PA, 1992; Vol. II, pp. 720-739. 
11. Pokharel, S. S.; Bishop, G. A.; Stedman, D. H. On-road remote sensing of automobile emissions in the Phoenix area: year 2; Tech Report Coordinating Research Council E-23-4; University of Denver: Denver CO, 2001; Available at http://www.feat.biochem.du.edu.

12. Schwartz, J. Facts not fear on air pollution: How regulators, environmentalists and scientists exaggerate the level and health risks of air pollution and impose counterproductive regulations. National Center for Policy Analysis No. 294, 2006; Available at http://www.joelschwartz.com/pdfs/Schwartz_NCPAair121106.pdf.

13. Harley, R. A.; Marr, L. C.; Lehner, J. K.; Giddings, S. N. Changes in motor vehicle emissions on diurnal to decadal time scales and effects on atmospheric composition. Environ. Sci. Technol. 2005, 39, 5356-5362.

14. Harley, R. A.; Hooper, D. S.; Kean, A. J.; Kirchstetter, T. W.; Hesson, J. M.; Balberan, N. T.; Stevenson, E. D.; Kendall, G. R. Effects of reformulated gasoline and motor vehicle fleet turnover on emissions and ambient concentrations of benzene. Environ. Sci. Technol. 2006, 40, 5084-5088.

15. Pokharel, S. S.; Bishop, G. A.; Stedman, D. H.; Slott, R. Emissions reduction as a result of automobile improvement. Environ. Sci. Technol. 2003, 37, 5097-5101.

16. Jimenez, J. L.; McClintock, P.; McRae, G. J.; Nelson, D. D.; Zahniser, M. S. Vehicle specific power: A useful parameter for remote sensing and emission studies. Proceedings of the ninth CRC On-Road Vehicle Emissions Workshop, Coordinating Research Council, Inc.; Atlanta, GA, 1999. 
17. Zhang, Y.; Bishop, G. A.; Stedman, D. H. Automobile emissions are statistically $\gamma$ distributed. Environ. Sci. Technol. 1994, 28, 1370-1374.

18. White, V. A.; Javaherian, H. U. S. Patent 5,392,598, 1995.

19. Haskew, H., personal communication.

20. U.S. Environmental Protection Agency; Available at http://www.epa.gov/otaq/mobile.htm.

21. Benson, J. D.; Burns, V.; Gorse, R. A.; Hochhauser, A. M.; Koehl, W. J.; Painter, J. L.; Reuter, R. M. Effects of gasoline sulfur level on mass exhaust emissions - Auto/Oil air quality improvement research program. Soc. Auto. Eng. 1991, 912323.

22. Stedman, D. H.; Bishop, G. A.; Aldrete, P.; Slott, R. S. On-road evaluation of an automobile emission test program. Environ. Sci. Technol. 1997, 31, 927-931.

23. Stedman, D. H.; Bishop, G. A.; Slott, R. S. Repair avoidance and evaluating Inspection and maintenance programs. Environ. Sci. Technol. 1998, 32, 1544-1545.

24. Wenzel, T.; Singer, B.; Slott, R. Some issues in the statistical analysis of vehicle emissions. J. Transport. Statist. 2000, 3, 1-14.

25. Stedman, D.H. EPA Overestimates the Benefit of Biennial I/M. Environ. Manager 1996, Dec. 27-29.

26. DeHart-Davis, L.; Corley, E.; Rodgers, M. O. Evaluating vehicle inspection/maintenance programs using on-road emissions data: The Atlanta reference method. Eval. Rev. 2002, 26, $111-$ 146. 
27. Lawson, D. R. "Passing the test" - Human Behavior and California's Smog Check program. J. Air \& Waste Manage. Assoc. 1993, 43, 1567-1575. 
Supporting Material

* This is a file for MOBILE6 input - DEN_05.IN

***************** Header Section $* * * * * * * * * * * * * * *$

MOBILE6 INPUT FILE

****************) Run Section $* * * * * * * * * * * * * * *$

DATABASE OUTPUT :

DAILY OUTPUT :

WITH FIELDNAMES :

DATABASE FACILITIES : ARTERIAL

DATABASE EMISSIONS : 2111111111

DATABASE VEHICLES : 2221111111111111111111111111

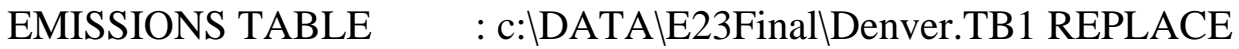

RUN DATA

EXPRESS HC AS VOC :

NO REFUELING :

> Evaluation year 2005 only

> Program data from inspection year 2000

$>$ Basic and Enhanced I/M Programs

> Pass/fail Idle only for all HDGV vehicles >1981

> Colorado 2005 I/M240 cutpoints for cars and trucks

I/M PROGRAM : : 1198220501 T/O 2500/IDLE 


\begin{tabular}{|c|c|}
\hline I/M MODEL YEARS & : 119811981 \\
\hline I/M VEHICLES & : 122222222222222 \\
\hline I/M STRINGENCY & : 121.0 (Pre 1981 stringency rate not applicable) \\
\hline I/M COMPLIANCE & $: 195.0$ \\
\hline I/M WAIVER RATES & : 1.00 .37 (Pre 1981 waiver rate not applicable) \\
\hline I/M GRACE PERIOD & $: 15$ \\
\hline I/M PROGRAM & : 2198220502 T/O IDLE \\
\hline I/M MODEL YEARS & : 219822050 \\
\hline I/M VEHICLES & : 211111222222222 \\
\hline I/M STRINGENCY & : 221.0 (Pre 1981 stringency rate not applicable) \\
\hline I/M COMPLIANCE & $: 295.0$ \\
\hline I/M WAIVER RATES & : 2 .00 .57 (Pre 1981 waiver rate not applicable) \\
\hline I/M GRACE PERIOD & $: 25$ \\
\hline I/M PROGRAM & : 3198220502 T/O IM240 \\
\hline I/M MODEL YEARS & : 319822050 \\
\hline I/M CUTPOINTS & : 3 05CUTPC.D \\
\hline I/M VEHICLES & : 321111111111111 \\
\hline I/M STRINGENCY & : 321.0 (Pre 1981 stringency rate not applicable) \\
\hline I/M COMPLIANCE & : 395.0 \\
\hline I/M WAIVER RATES & : 3.00 .82 (Pre 1981 waiver rate not applicable) \\
\hline I/M GRACE PERIOD & :35 \\
\hline
\end{tabular}




\begin{tabular}{|c|c|}
\hline I/M PROGRAM & : 4198220502 T/O IM240 \\
\hline I/M MODEL YEARS & : 419822050 \\
\hline I/M CUTPOINTS & : 4 05CUTPT.D \\
\hline I/M VEHICLES & : 412222111111111 \\
\hline I/M STRINGENCY & : 421.0 (Pre 1981 stringency rate not applicable) \\
\hline I/M COMPLIANCE & $: 495.0$ \\
\hline I/M WAIVER RATES & : 4.001 .12 (Pre 1981 waiver rate not applicable) \\
\hline I/M GRACE PERIOD & $: 45$ \\
\hline ANTI-TAMP PROG & : 8275012222222222222212 095. 22111112 \\
\hline FUEL PROGRAM & $: 3$ \\
\hline$* * * * * * * * * * * * * * * * \quad$ Scen & Irio Section $\quad * * * * * * * * * * * * * * *$ \\
\hline SCENARIO RECORD & : WINTER Enhanced I/M - CY2005 \\
\hline CALENDAR YEAR & : 2005 \\
\hline MIN/MAX TEMP & : 27.052 .0 \\
\hline FUEL RVP & $: 12.5$ \\
\hline ALTITUDE & $: 2$ \\
\hline OXYGENATED FUELS & : 0001.00 .000 .0192 \\
\hline$* * * * * * * * * * * * * * * \quad$ Scen & Irio Section $* * * * * * * * * * * * * * *$ \\
\hline SCENARIO RECORD & : Summer Enhanced I/M - CY2005 \\
\hline CALENDAR YEAR & : 2005 \\
\hline MIN/MAX TEMP & : 58.078 .0 \\
\hline
\end{tabular}


End of This Run $\quad * * * * * * * * * * * * * * *$

FUEL RVP

ALTITUDE

$* * * * * * * * * * * * * * *$

: 8.5

$: 2$
END OF RUN

nd of This Run $* * * * * * * * * * * * * * *$ 